Centre for Theoretical Studies, Indian Institute of Science, Bangalore

\title{
Social Organisation in the Indian Wasp Ropalidia cyatbiformis (Fab.) (Hymenoptera: Vespidae)
}

\author{
By Raghavendra Gadagkar and N. V. Joshi
}

With 7 figures

Received: May 27, 1982

Accepted: December 6, 1982

\section{Abstract and Summary}

Multivariate analysis of time-activity budgets of several individually marked adults of the primitively eusocial Indian wasp Ropalidia cyathiformis shows the existence of three behavioural clusters (or castes) which are called Fighters, Sitters and Foragers, after their most distinguishing features. The principal egg layers who are also the most dominant individuals are the Fighters. The Sitters are idlers who are speculated to be 'hopeful queens' and the foragers are the principal worker force of the nests. Such a behavioural differentiation does not normally appear to change drastically with age of the animal. Nor does it change when an individual leaves a nest and founds or joins a different nest. It probably could however change in response to major penturbations such as death of the queen. Males as a class do not form a separate cluster distinct from the females but may either be Sitters or Foragers. Comparison of these results with those of $R$. marginata, a related social wasp, whose queens are Sitters, suggests that there is a higher level of reproductive competition in R. cyathiformis.

\section{Introduction}

Ropalidia is a large genus of exclusively Old World tropical paper wasps. About 28 species have been reported from India (GUPTA and DAs 1977) while a large number of species are known from Africa, South-east Asia and Australia (RICHARDS 1978; VAN DER VECHT 1962). However, biological studies on this genus have almost been non-existent although the genus itself has been recognised to be of special interest among the Vespidae (Jeanne 1980). In recent years two species $R$. marginata and $R$. cyathiformis have been the subject of a series of biological studies (GADAGKAR 1980; GADAGKAR and JOSHI 
$1982 \mathrm{a}, \mathrm{b}, 1983$; Gadagkar and West-Eberhard in prep.; Gadagkar et al. 1978, 1982; GADGIL and MAHABAL 1974). The nests of both these species consist of small open combs initiated by one or several females (foundresses) and their social systems may be classified as primitively eusocial.

Eusocial insects are characterised by three properties, cooperative brood care, reproductive division of labour and overlap of generations (MICHENER 1974; WILson 1971). Among these, primitively eusocial forms are those that show no morphological differentiation between the adults and highly eusocial ones are those that exhibit well defined morphological castes. Termites, most ants and some bees are highly eusocial and have been well studied for many years (Breed et al. 1982; Michener 1974; Wilson 1971, 1975). Several species of wasps and bees are primitively eusocial and these are receiving increasing attention in recent years primarily because of the hope that, by virtue of their primitiveness, an understanding of their societies would throw light on questions concerning the origin and evolution of social behaviour (BROTHERs and Michener 1974; Greenberg 1979; JeanNe 1972, 1980; LitTe 1977, 1979, 1981; Marino Piccioli and Pardi 1970, 1978; Pardi and Marino Piccioli 1970, 1981; Pickering 1980; Strassmann 1981a, b; West-Eberhard 1969).

The picture that has begun to emerge from these studies suggests that not only do these primitively eusocial forms lack any significant morphological caste differentiation but the role that an individual might play in a nest is rather flexible. In many instances a colony consists of several females each of which is physiologically capable of assuming the role of the queen but only one or a small number of them actually do so and this is decided largely by social interactions (PARDI 1948; WEST 1967). When only one or a small number become queens, the others sometimes stay on at the nest and assume subordinate worker roles (PARDI 1948; WEST 1967) and at other times they leave the colony to found their own nests. It is this flexibility in roles that makes the primitively eusocial species particularly attractive model systems for investigating the forces that might lead to the evolution of sterile castes - a prime question in sociobiology.

The first step in such an investigation is to understand in more detail and in quantitative terms the social organisation that characterises the social groups. It is essential to know in precise terms the behaviour of different individuals comprising a social group rather than merely identifying egg-layers from sterile ones. Here an attempt has been made to do this with $R$. cyatbiformis. The main aim has been to study the behavioural differences between adults on a nest. Preliminary observations showed that all the adults are capable of and in fact do perform most of the behaviours that form the repertoire of the species. The differences between individuals are therefore more likely to be quantitative rather than qualitative. Hence, time-activity budgets have been constructed for several individually identified members of a few nests. Analysis of such data by multivariate statistical techniques reveals the presence of three behavioural clusters that we call Fighters, Sitters and Foragers after their distinguishing features. 


\section{Materials and Methods}

\section{A. Study Animal}

This study was conducted on a group of 4 separate nests built on a metallic pole (one nest) and on the leaves of a croton bush ( 3 nests) on the grounds of the Indian Institute of Science, Bangalore $\left(13^{\circ} 00^{\prime} \mathrm{N}\right.$ and $\left.77^{\circ} 32^{\prime} \mathrm{E}\right)$, India, between 24 April and 21 June 1980 . All the adults of the colonies were individually identified by marking with spots of coloured paint without removing them from the nest. The marking was done immediately after emergence of an adult. A census of all the adults present at the nest was taken before $05.30 \mathrm{~h}$ since none of them left the colony before this time. A list of the animals, their sex, and the nests to which they belonged is given in Table 1.

\section{B. Sampling Methods}

Three kinds of sampling methods were used in the study (Altmann 1974).

1. Ad libitum sampling was employed for constructing an ethogram, i.e., a descriptive catalogue of the behavioural repertoire of the species, and to get preliminary information on the basis of which subsequent sampling methods were chosen.

2. Instantaneous scanning of the behavioural states of all animals in a colony was performed at randomly chosen times.

3. All occurrences of rare behaviours. Some behaviours that appeared to be relatively rare on the basis of ad libitum sampling were recorded during separate 5-min sessions during which all occurrences of each such behaviour by any animal in the colony were recorded. Here every behaviour was treated as an event and no information on its duration was recorded.

All sampling sessions were begun and terminated by time-contingent rules using a stop watch accurate to $0.1 \mathrm{~s}$. Observations were made for a total of $225 \mathrm{~h}$ which included ad libitum observations, 282 instantaneous scanning sessions and 51 all occurrences recording sessions. Ad libitum observations showed that the wasps were relatively inactive between 18.00 and 6:00 h. All sampling sessions were therefore chosen randomly between 06.00 and $18.00 \mathrm{~h}$. All data were recorded in a pre-coded form on coding sheets in an 80 column format ready to be punched on computer cards. The data were analysed using a DEC 1090 computer at the Indian Institute of Science, Bangalore.

\section{Analysis of Data}

\section{Time-Activity Budgets}

Time-activity budgets, namely, the proportion of time spent in different behaviours by different animals, were estimated using data from instantaneous scans. The following 6 behaviours, Sit and Groom, Raise Antennae, Raise Wings, Walk, In Cells and Absent from Nest, descriptions of which are given below under the section on behavioural repertoire, are the most prominent ones accounting for approximately $95 \%$ of a wasp's time. Data on these 6 behaviours were hence chosen for analysis.

Table 1: Animals used in the study

\begin{tabular}{|l|c|c|c|c|c|c|c|c|c|c|c|c|c|c|c|c|}
\hline Animal number & 1 & 2 & 3 & 4 & 5 & 6 & 7 & 8 & 9 & 10 & 11 & 12 & 13 & 14 & 15 & 16 \\
\hline Sex & M & F & M & F & F & F & F & M & M & F & F & F & F & F & F & F \\
\hline Nest & 1 & 1 & 1 & 1 & 1 & 1 & 1 & 1 & 1 & 1 & 1 & 1 & 1 & 1 & 1 & 1 \\
\hline Animal number & 17 & 18 & 19 & 20 & 21 & 22 & 23 & 24 & 25 & 26 & 27 & 7 & $12^{*}$ & $17^{4}$ & $19^{*}$ & 22 \\
\hline Sex & F & F & F & F & F & F & F & F & F & F & F & F & F & F & F & F \\
\hline Nest & 1 & 1 & 1 & I & 1 & 1 & 1 & 1 & 1 & 2 & 3 & 4 & 4 & 4 & 4 & 4 \\
\hline
\end{tabular}




\section{Frequencies of Rare Behaviours}

Certain behavioural categories occurred rather infrequently making it difficult to accurately estimate the proportion of time spent in them using the instantaneous scans. The hourly frequencies with which these behaviours were performed were therefore estimated from the all occurrences recording sessions. Five of these behavioural categories, Dominant and Subordinate Behaviours, Dominance Display, Bringing Food, Pulp or Liquid and Egg Laying, all of which are defined below, are the most frequent ones and our analysis is thus restricted to these.

\section{Behavioural Repertoire}

The behavioural repertoire of $R$. cyatbiformis was classified into 54 distinct behavioural categories (GADAgKaR, unpubl. obs.; GADAGKar and WeST-EBERHARD in prep.). The definitions of the 11 most prominent ones are given below:

(i) Sit and Groom: By sitting is meant sitting without doing anything in particular and apparently without being alert to any external disturbance. In this position the wasps sit with their bodies held compactly in one plane with legs and wings drawn close to the body and the antennae lowered. Grooming is always self-grooming and no allogrooming has been observed. The most frequent forms of grooming involve rubbing posterior legs against each other and against wings and abdomen; anterior legs against mouth parts, antennae and head; and antennae against mouth parts.

(ii) Raise Antennae: This involves sitting with wings drawn close to the body but the antennae raised above the body plane. There is a transition from Sitting to Raising Antennae when there is any disturbance.

(iii) Raise Wings: This involves sitting with both antennae and wings raised above the body plane. The legs may still be folded or may be stretched so as to raise the body above the substratum. Raising Antennae is followed by Raising Wings if the disturbance continues.

(iv) Walk: The wasps walk on the face and back of the nest; when they walk, they sometimes reach different cells in the nest and sometimes other adults sitting on different parts of the nest.

(v) In Cells: The wasps get inside the cells with only their head or the entire body, either simply 'inspecting' the contents or receiving secretions from the larvae or transfering liquid to larvae.

(vi) Absent from Nest: Temporary Absence from nest is considered here as one category although a wasp temporarily absent trom the nest may return with food, pulp, liquid or nothing.

(vii) and (viii) Dominance and Subordinate Bebaviour: A variety of dominance and subordinate behaviours are shown by this species (GADAGKAR and JosHI 1982b). Very briefly, dominance behaviour (by definition) consists of one of the following: climbing on top of another individual and attempting to bite its mouth parts; sitting on top of another individual, sometimes for several min on end; sitting close to another individual and holding one of the latter's legs or antennae in its mouth; chasing; nibbling or pedking at another individual. In all such interactions the individual towards which such dominance behaviour is directed remains passive or attempts to withdraw and this, by definition, is called subordinate behaviour.

(ix) Dominance Display: Dominant individuals often showed certain kinds of behaviour which are termed Dominance Displays. These behaviours involve a rapid up and down or side to side movement of the abdomen or a single rapid flap of the wings. One of these, namely rapid side-to-side movement of the abdomen, appeans to correspond to 'Lateral Vibrations' as defined by GAMBOA and DEw (1981) who also suggested that it was involved in adult dominance communication.

(x) Bringing Food, Pulp or Liquid: On occasions wasps returned to the nest with food, pulp or liquid. Both because we observed these events very rarely and also because we could not always distinguish between food, pulp or liquid, this is treated here as a single behavioural category.

(xi) Egg-laying: This is self-explanatory and needs no description. 


\section{Principal Components Analysis}

From the time-activity budgets, every individual can be characterised by the proportion of time it spends in each of the 6 different behaviours, i.e. in terms of 6 variables, which may be correlated. For the purpose of analysis, however, it is desirable to have variables which are uncorrelated and also to reduce the number of variables while retaining most of the information in the data. The method of principal components analysis (FreY and Pimentel 1978) yields such a new set of uncorrelated variables. These new variables are linear combinations of the old variables; each old variable being multiplied by a weightage term which reflects the extent of variance contained in it. The new variables are maximally powerful in bringing out the differences between individuals in the sense that, of all the possible linear combinations, the proportion of total variance accounted for by each of the new variables is maximal (ANDERBERG 1973). In addition, it is often possible that only a small number of these new variables account for almost all the variance between the individuals.

\section{Hierarchical Cluster Analysis}

Using the proportion of time spent in the six activities by different individuals as input data, Pearson product-moment correlation was obtained as an index of similarity between pairs of individuals (DE GHETT 1978). Using these indices of similarity, a hierarchical cluster analysis was performed with the single linkage algorithm (DE GHETT 1978).

\section{Results}

\section{A. Time-Activity Budgets}

The time-activity budgets of 32 individually identified animals belonging to 4 nests (Fig. 1) reveal that adults of $R$. cyatbiformis spend $95 \pm 6$ (mean \pm

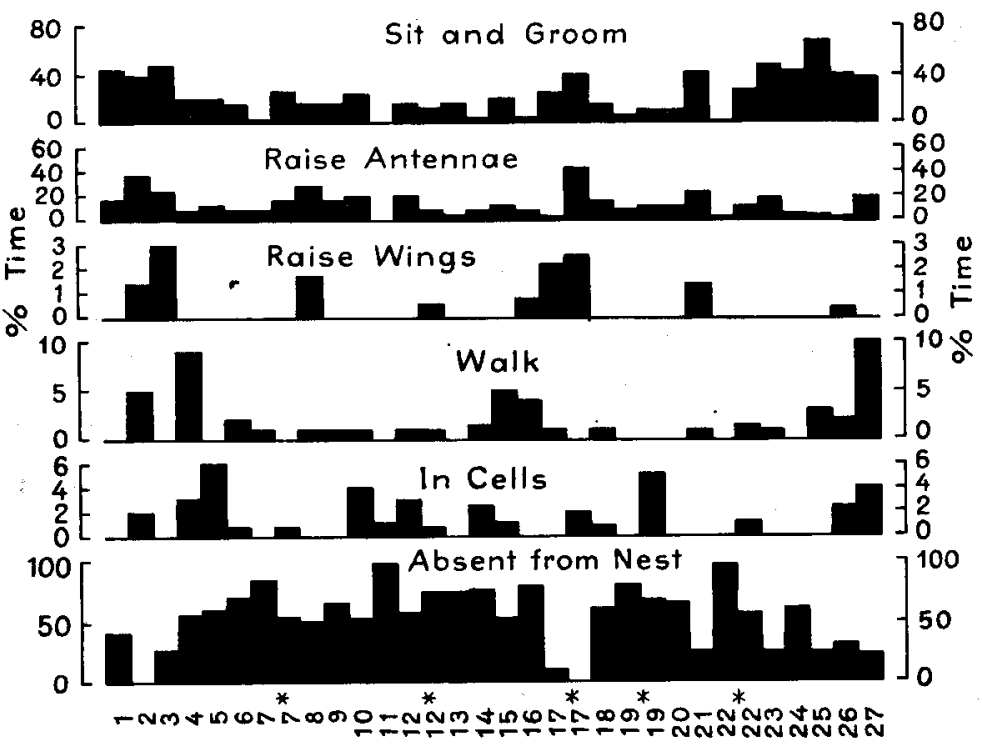

Fig. 1: Time activity budgets of 32 individually identified animals from 4 nests of $R$. cyatbiformis for 6 behaviours. The animals are numbered serially and their sex and nest affiliations are listed in Table 1 . When a wasp lefit a nest to found or join another nest it was treated 
SD) \% of their time in the 6 activities Sit and Groom, Raise Antennae, Raise Wings, Walk, In Cells and Absent from Nest. Note that there is little variation in the total amount of time spent by different individuals in these 6 activities taken together. However, the manner in which they allocate their time among these 6 activities is highly variable suggesting that there is indeed a quantitative variation among individuals in their behaviour. This is strikingly brought out in Fig. 1. The time spent in Absence from Nest for example, varies between $O$ and $98 \%$ and similarly, the time spent in Sit and Groom between 0 and $68 \%$.

\section{B. Principal Components Analysis}

The results of the principal components analysis are shown in Table 2. The first principal component accounts for $89.91 \%$ of the total variance with Absent from Nest as its dominant term (weightage $=0.8442$ ). The second principal component whose dominant term is Sit and Groom (weightage = 0.7507 ) accounts for $8.23 \%$ of the total variance. Thus the first two principal components together account for $98.14 \%$ of the total variance and can therefore be considered adequate for describing the individuals. The behavioural description of the individuals has thus been reduced from a six-dimensional to a two-dimensional problem. Moreover, the original variables, namely, the proportions of time spent in different activities, are often correlated with each other. The new variables, namely the amplitudes associated with the principal components, are always uncorrelated. Representing each individual as a point in the coordinate space of the associated amplitudes of the first two principal components should thus be very effective in bringing out the differences among individuals. This is illustrated in Fig. 2. The points (each point corresponding to a wasp) fall into three clusters. This has been confirmed by the method of nearest centroid; the distance between any individual and the centroid of the cluster to which it belongs is less than its distance from the other two centroids. Individual 25 alone does not fall into any of the three clusters.

Table 2: Eigen vectors of principal components, Eigen values, percentage of variance, and cumulative percentage of variance

\begin{tabular}{|l|c|c|c|}
\hline \multirow{2}{*}{ Behaviour } & \multicolumn{3}{c|}{ Principal components } \\
\cline { 2 - 4 } & 1 & 2 & 3 \\
\hline Sit and Groom & -0.4773 & 0.7507 & 0.3926 \\
\hline Raise Antennae & -0.2425 & -0.6100 & 0.6560 \\
\hline Raise Wings & -0.0162 & -0.0380 & 0.0574 \\
\hline Walk & -0.0219 & -0.0095 & -0.4905 \\
\hline In Cells & -0.0036 & -0.0357 & -0.1141 \\
\hline Absent from Nest & 0.8442 & 0.2481 & 0.3983 \\
\hline Eigen value & $2.9 \times 10^{4}$ & $2.6 \times 10^{3}$ & $3.8 \times 10^{2}$ \\
\hline Percentage of variance & 89.91 & 8.23 & 1.19 \\
\hline Cumulative percentage of variance & 89.91 & 98.14 & 99.33 \\
\hline
\end{tabular}




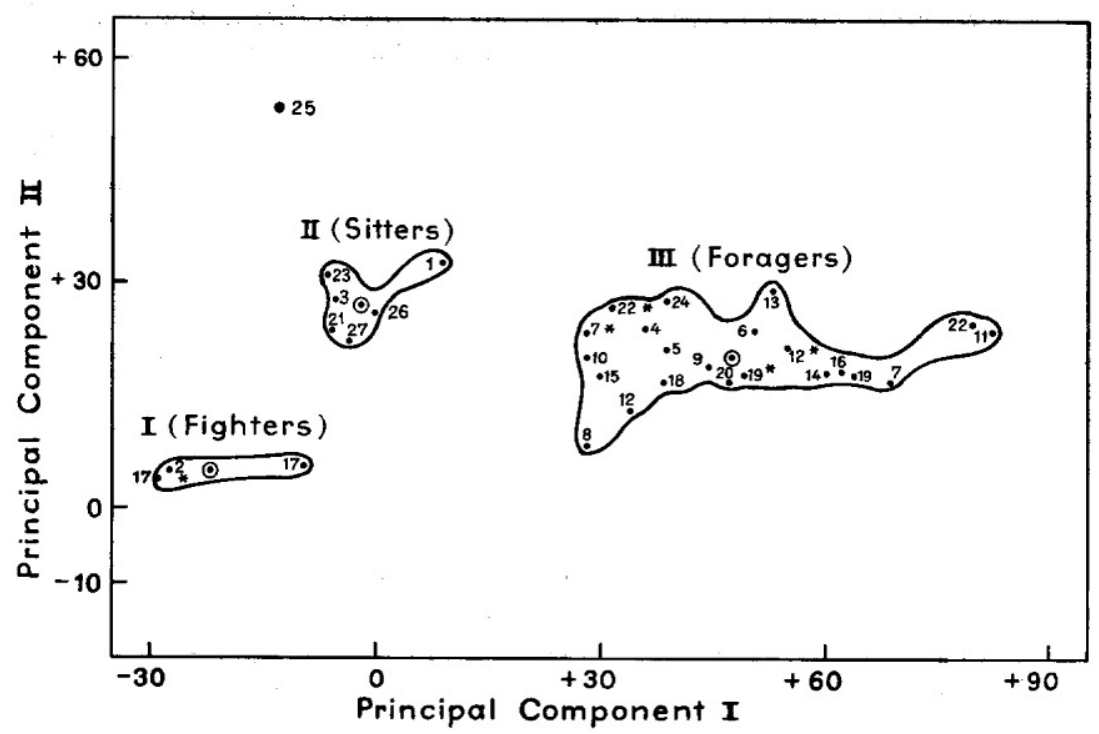

Fig. 2: Behavioural clusters of $R$. cyathiformis. Time-activity budgets of 32 wasps are shown as points in the coordinate space of the first two principal components. The points fall into three clusters by the criterion of nearest centroid. Circled dot $=$ centroid

It is possible that this is because of sampling error since individual 25 is the animal on which we have the least data.

It is important to emphasize that the three clusters emerged as a result of an objective analysis of the data and no a priori assumptions were made regarding the criteria to be used for classification or the number of clusters required. The behavioural categories used in the analysis were chosen neither subjectively nor blindly. We chose those 6 behaviours that had the highest ranks in the proportion of time the wasps devoted to them.

\section{Hierarchical Cluster Analysis}

An independent method of classification, namely, hierarchical cluster analysis using the Pearson product moment correlation as an index of similarity between individuals gives identical clusters (Fig. 3). Here again, individual 25 is separated from all the others and one can recognize three clusters with identical composition as those of the clusters obtained from principal components analysis. This complete concurrence is interpreted here as an indication of the robustness of the clusters we have obtained. Moreover the three clusters obtained here were found to be significantly different from each other $(\mathrm{p}<0.05)$ by the randomization test described by SOKAL and ROHLF $(1969)$.

\section{Mean Profiles of the three Clusters}

In order to understand the biological significance of the clusters we have obtained, let us go back to the time-activity budgets and look at the mean 


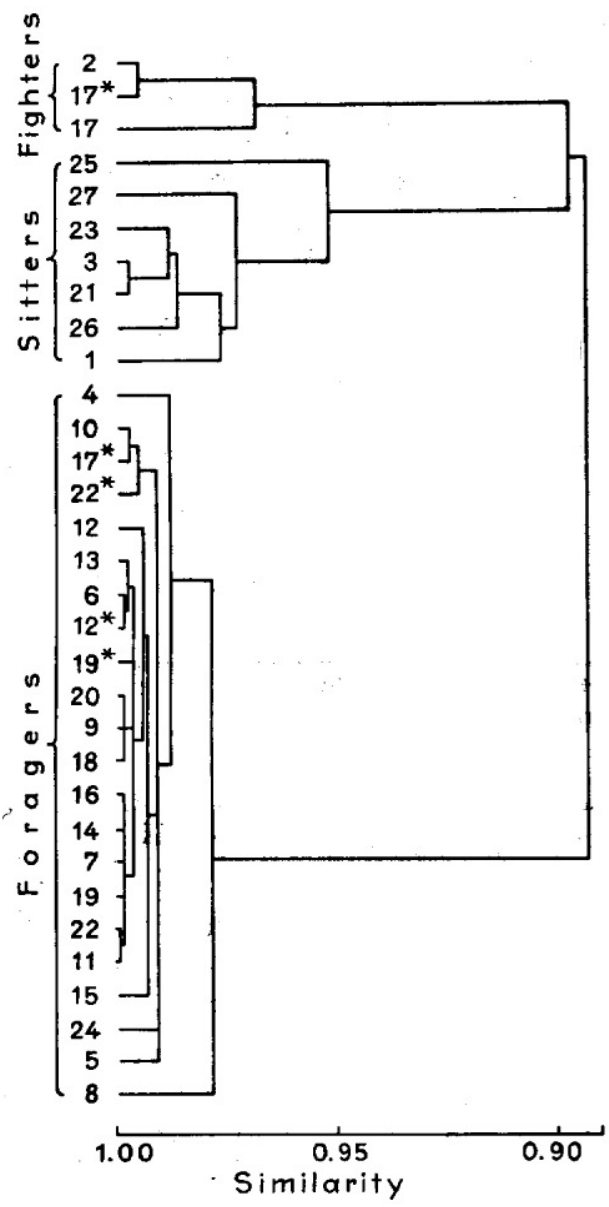

Fig. 3: Hierarchical cluster analysis. Timeaotivity budgets of the same 32 animals as in Fig. 2 are used. The similarity between individuals shown is Pearson product moment correlation calculated using the proportion of time spent in 6 behaviours. The method of single linkage algorithm is used for clustering

behavioural profiles of each cluster. These are plotted in Fig. 4. The clusters were obtained by a consideration of all the 6 activities simultaneously and any two clusters therefore need not necessarily be significantly different from each other in any single activity alone. However, Fig. 4 reveals that Absent from the Nest is obviously the most significant attribute of cluster III. Because wasps in this cluster returned to the nest with food, pulp or liquid more of ten than other wasps (Fig. 5) this cluster will be called "Foragers". Cluster II has the highest rank for Sit and Groom (Fig. 4); this will hence be known as "Sitters". Cluster I ranks slightly lower than cluster II in Sit and Groom and slightly higher than cluster II in Raise Antennae (Fig. 4). At this point let us look at some of the additional data that were obtained from sampling sessions in which all occurrences of certain rare behaviours such as Dominance Behaviour, Subordinate Behaviour, Dominance Display, Bringing food, pulp or 
Fig. 4: Mean time-budgets for the clusters obtained in Figs. 2 and 3. The mean proportion of time spent, per animal, in each of the 6 behaviours used in the analysis is shown for each cluster

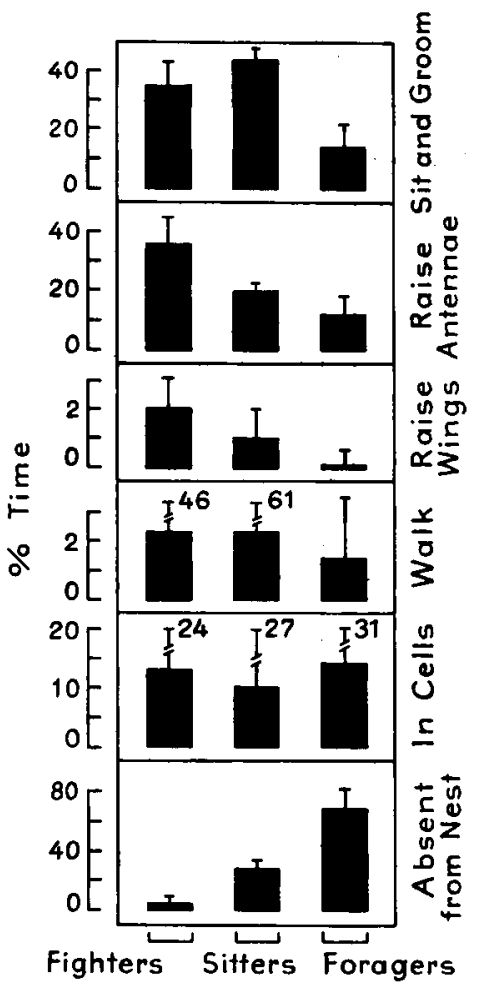

liquid and Egg Laying were recorded (see Materials and Methods). These data are not in the form of time-activity budgets but as frequencies of each behaviour for each animal per hour (except in the case of egg laying). Since several animals did not perform some of these behaviours at all, it seemed inappropriate to simply consider the mean rate per animal in a given cluster. We have therefore considered both the proportion of animals performing a given behaviour and the mean rate among the animals that performed the behaviour in question (Fig. 5). Notice that these quantities are correlated. It now becomes obvious that cluster $I$ is strikingly different from the other two clusters in showing a high level of Dominance Behaviour and Dominance Display and a complete absence of Subordinate Behaviour. This cluster will therefore be called "Fighters". To summarise, multivariate analysis of time-activity budgets of individually identified adults of Ropalidia cyatbiformis nests shows the presence of three clusters or behavioural castes namely, Fighters, Sitters and Foragers. The names Fighters, Sitters and Foragers are derived from the most important correlate of each cluster and are used only for convenience. It should by no means be assumed that Sitters only sit or that Fighters do not sit. The clusters were derived by a simultaneous consideration of all 6 behaviours; most wasps perform most behaviours and the differences are only quantitative. 


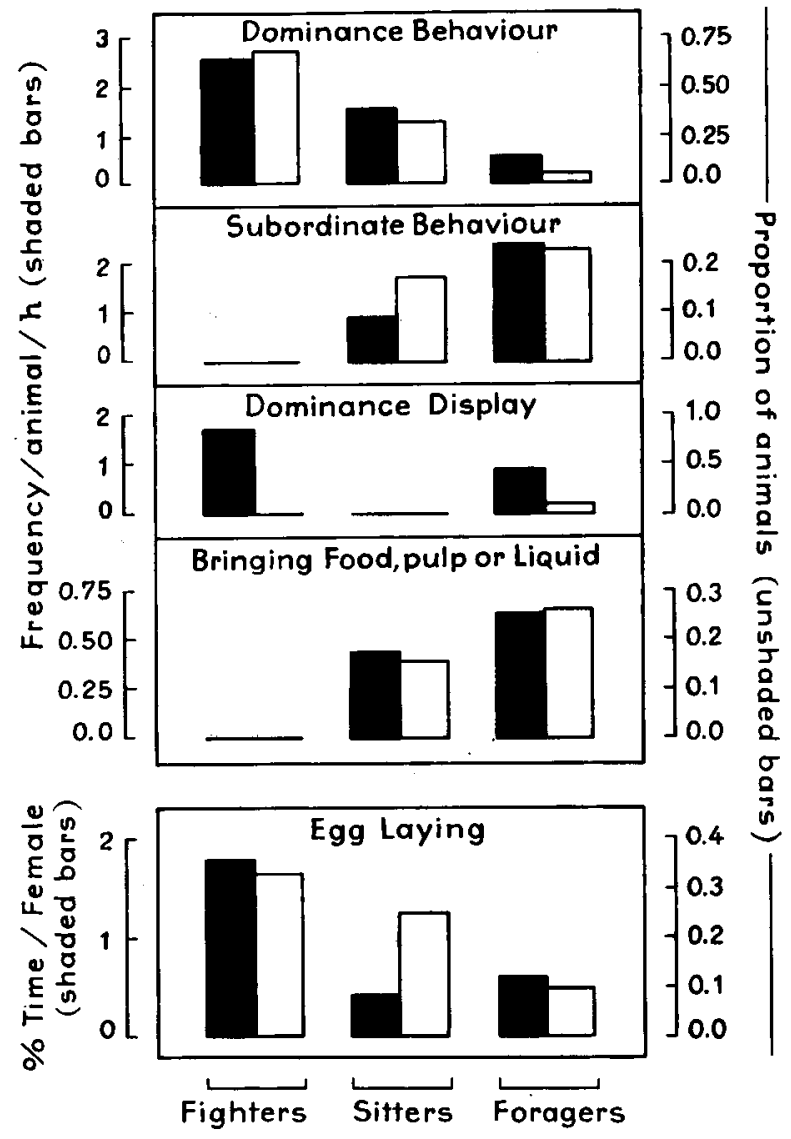

Fig. 5: Mean frequencies of, or percentage time spent in rare behaviours. In each cluster the proportion of animals showing a given behaviour (unshaded bars) and the mean frequency per $h$ per animal amongst those showing the behaviour (shaded bars) are shown. In the case of egg laying the propontion of females that laid eggs (unshaded bars) in each cluster and the mean percentage of time spent by the females that laid eggs (shaded bars) are shown

\section{E. Duration of Residence of Adults on a Nest}

A question of obvious interest is whether these behavioural characteristics of individuals keep changing drastically with time or remain rather fixed. It is essential to have an estimate of the life span of adults before attempting to understand any changes in behaviour with age. The fact that all wasps were individually identified by paint marks and that a census of all those present on the nest was made every two days provides a record of the duration of residence on a nest for 94 wasps. When a wasp disappears from one nest, it may either have died (mortality) or, founded or joined another nest (emigration). In most cases these two components cannot be distinguished and what is presented here is simply the duration of residence on a given nest. Even when a wasp was known to leave one nest and found another, its duration of residence on each nest was calculated separately. The duration of residence of wasps on a nest varied from 1 to 134 days. The 96 records constitute 78 female and 16 male wasps. The mean duration of residence for females was $24 \pm 26$ 


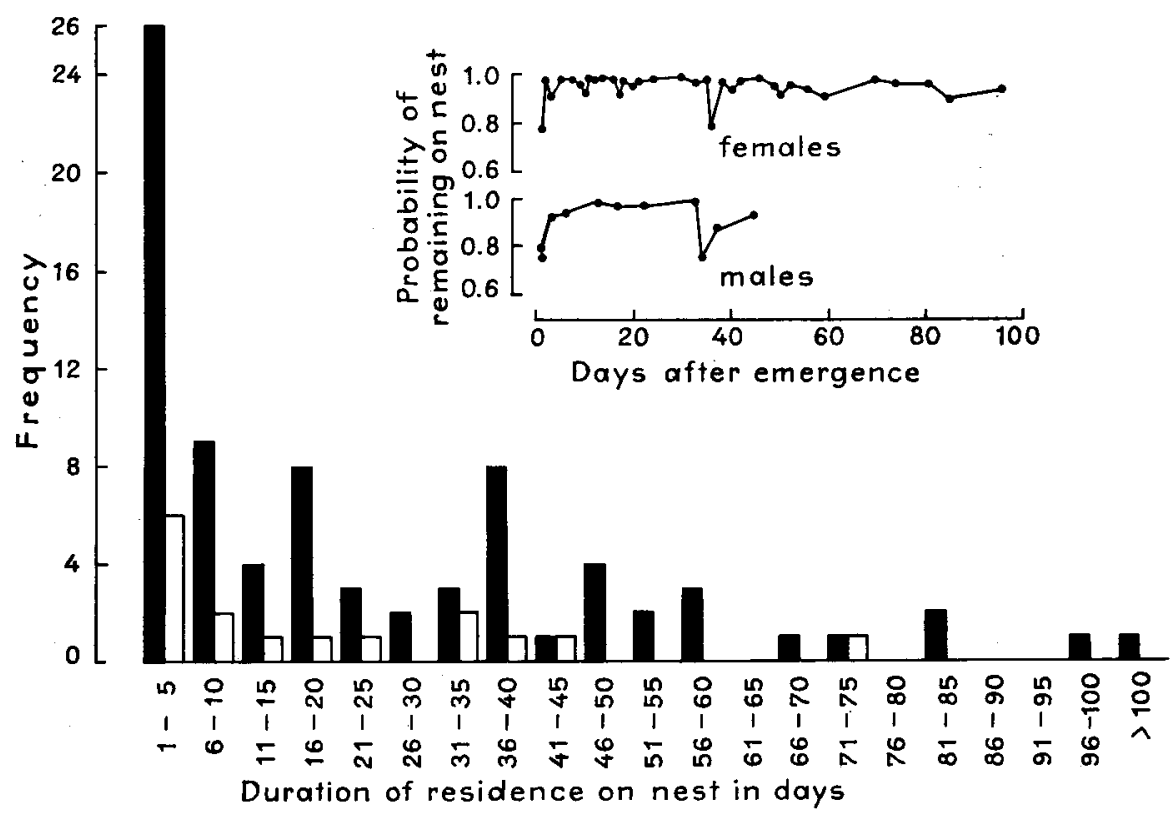

Fig. 6: Frequency distribution of residence times on a given nest of 78 female (shaded bars) and 16 male (unshaded bars) paint-marked wasps of $R$. cyathiformis. The age-specific dayto-day probability of remaining at the same nest (inset) of $0.90 \pm 0.09$ for males and $0.95 \pm 0.05$

for females is nearly constant with age. Notice that most points lie between 0.90 and 1.0

(mean $\pm S D$ ) days and $19 \pm 21$ (mean $\pm S D$ ) days for males. The frequency distribution of residence times is shown in Fig. 6. It may be mentioned parenthetically that the day-to-day probability of survival having values of $0.90 \pm$ 0.09 for males and $0.95 \pm 0.05$ for females does not seem to vary with age (see inset in Fig. 6). This seems to suggest that mortality forms a very large component of the present estimates and emigration only a small component. The reasoning is as follows. Mortality seems to occur largely during the foraging trips, for the wasps simply do not return to their nests. They are probably lost or preyed upon. We do not expect the probability of these events to depend upon the age of the wasp while it is reasonable to expect the probability of emigration to found or join new nests to show some age dependence.

\section{F. Developmental Changes in Behaviour}

Thus far, all the behavioural data available on each wasp throughout the period of observation were pooled to give an average time-budget for each wasp. To understand the effect, if any, of the age of the animal on its behaviour it would be necessary to construct separate time-activity budgets for each wasp at different times in its life span. Unfortunately, data are insufficient to permit such a break up for all the animals. However, for 9 animals (numbers 1, 2, 4, 6, 7, 9, 17, 18, 21 in Table 1 and Figs. 1, 2 and 3) time activity 
budgets have been prepared for each fortnight of their lives. With these time budgets their corresponding positions in the coordinate space of the principal components in Fig. 3 are computed. The results, illustrated in Fig. 7, show that the fortnightly behavioural profiles are rather close to each other and to their corresponding mean profiles. This suggests first, that most animals did not drastically change their behavioural profiles with age and second, that using the life-time mean behavioural profiles as we have done, does not therefore distort the picture to any significant extent. It must be pointed out that in the first week of their lives, however, all wasps do little other than Sit and Groom (GADAGKar unpubl. obs.). After this they seem to adopt a certain time-budget for the rest of their lives. This does not of course mean that the time-budgets cannot change in response to such drastic perturbations as death of the queen or of a significant fraction of the foragers. In fact our preliminary results indicate that some individuals change their time-budgets to become replacement queens upon removal of the original queen (GADAGKAR unpubl. obs.). We therefore make the assumption that the time-budgets are in fact flexible in interpretating the biological significance of the clusters (see Discussion). The results in this section merely show that, in the absence of any major perturbations, most wasps do not change their time-budgets during their life span.

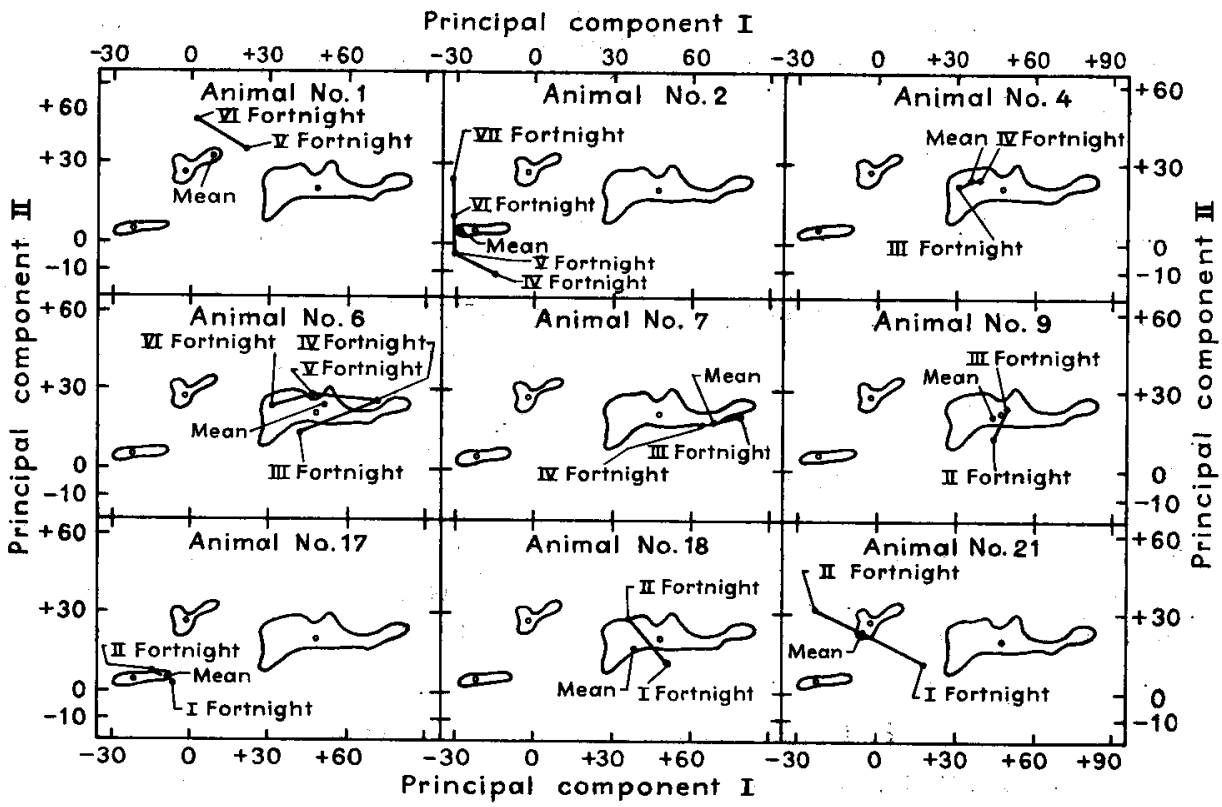

Fig. 7: Age dependent changes in behaviour. For 9 animals with large amounts of data, the time-activity budgets are calculated separately for each fortnight of their life (for those fortnights that data were available). These fortnightly time-budgets are used to compute their corresponding positions in the coordinate space of the first two principal components in Fig. 2 , There are 9 panels, one for each animal. The outline and centroid of each cluster and the position of the mean and all available fortnightly time budgets for the animal under consideration are shown in each panel 


\section{G. Behaviour of Males}

Males as a class do not differ from females on the basis of the 6 behaviours used in this analysis. Notice from Table 1 that four of the animals used in this analysis (animal numbers 1, 3, 8 and 9) were males. In $R$. cyathiformis the males remain at the nest and do not disappear immediately after emergence as in the case of Ropalidia marginata (GADAGKAR and JosHI 1982 b, 1983) (Fig. 6). It has therefore been possible to construct time-activity budgets for the males as well. Of the four males, two (animals 1 and 3) fall in cluster II (Sitters) and the other two (animals 8 and 9) fall into cluster III (Foragers). It may seem surprising that two males are in a cluster that we call Foragers. We have never observed a male to bring anything back to the nest. But we have occasionally observed males to feed larvae with food taken from other individuals. The males did spend a considerable portion of their time away from the nest. It is possible that they foraged for their own food and consumed it before returning to the nest. On the other hand, it cannot be ruled out that the males in this species sometimes bring food and feed the larvae. For a number of examples of male social wasps feeding larvae, see HunT and Noonan (1979). Alternatively the situation could be similar to that recorded in Mischocyttarus labiatus by LITTE (1981). In this species too, males are produced rather early in the colony cycle and remain at the nest throughout their lives, soliciting nectar and food from returning foragers, but spend about $4 \mathrm{~h}$ each day patrolling distant sites where mating presumably occurs.

\section{H. Behaviour of Individuals after Switching Nests}

When wasps left an existing nest and went on to found new nests nearby (Table 1), the data on each wasp on each nest were treated separately. As seen from Table 1, animals 7, 12, 17, 19 and 22 left their old nests and on their new nests they are labelled $7^{*}, 12^{*}, 17^{*}, 19^{*}$ and $22^{*}$ respectively. It is interesting that in each case the animal falls into the same cluster before and after it switched nests. This, we believe, gives further support to the idea that an individual adopts a certain behavioural profile and retains that profile for most of its life time. Notice the very significant fact that this is also true of an individual that was not an egg layer in the old nest but was the sole egg layer on the new nest (17 and $\left.17^{*}\right)$.

\section{Discussion}

Multivariate analysis of time-activity budgets of the social wasp $R$. cyathiformis shows the presence of three behavioural clusters which we have called Fighters, Sitters and Foragers on the basis of their distinguishing features. Recall that such a behavioural differentiation has been detected despite the absence of any obvious morphological differentiation.

It should be emphasized that Egg-Laying itself has not been used as one of the activities in this analysis. The reasons for this were two-fold. Firstly, Egg-Laying itself takes only a very small proportion of time, whereas we were 
primarily interested in classifying the wasps on the basis of how they distributed the bulk of their time between different activities without any pre-conceived notions of which activities were important. Secondly, eusocial insects have long been known to be differentiated into reproductives and non-reproductives. What is not known in many species is how this differentiation is correlated with the overall behaviour of the individuals. This is indeed what we can begin to understand for $R$. cyatbiformis from the present study. Having obtained the classification without using egg-laying as one of the input parameters, we can now look at the data on Egg Laying and other rare behaviours shown in Fig. 5.

The cluster that we call Fighters has three representatives: 2, 17 and $17^{*}$. Animal no. 2 was the most dominant wasp on nest 1 and laid most of the eggs on this nest. Animal no. 17 belonged to the same nest but was not observed to lay any eggs. However, it subsequently left this nest to found a new one of its own where it was the principal egg layer. Its time-budget on the new nest is analysed separately and represented as $17^{*}$. Two principal egg layers (animals 2 and $17^{*}$ ) and one potential egg layer (animal 17) thus constitute this cluster. This we believe is evidence of the biological significance of the behavioural classification we have obtained. Wasps in this cluster have two distinctive features. One is that they show a very high frequency of Dominance Behaviour and Dominance Display. Second, they show the highest frequency of sitting with Raised Antennae. Sitting with Raised Antennae, we suspect, serves the function of guarding the nest and its brood against parasites and predators. This is supported by the fact that the wasps immediately raise their antennae at the slightest disturbance. Since the principal and potential egg layers are the Fighters, it appears that being dominant over their nest mates is important for these individuals to maintain their status as principal or potential egg layers.

The second cluster consists of Sitters, individuals that spend more time sitting and grooming than others. Two of these, individuals 26 and 27, were the foundresses of nests 2 and 3, respectively, and were attending their nests without the aid of any co-foundresses or workers during the period of data collection. An obvious question that comes to mind is the role of the rest of the individuals of this cluster in the social organisation of the species. Every wasp spends the first few days of its life doing little other than sitting and grooming but the Sitters in this cluster obviously represent something quite different. Data in Fig. 7 have demonstrated that there are no significant developmental changes in behaviour and that a Sitter continues to be a Sitter even in the 5th and 6th fortnight of its life (see animal 1 in Fig. 7 for example). It is interesting to speculate that these individuals are "hopeful queens" (see WEST-EBERHARD 1978) who may have some chance of becoming dominant egg-layers such as the Fighters. They may thus be avoiding performing risky and energy consuming tasks such as Foraging.

A large number of individuals belonged to the cluster Foragers. These individuals spend a great deal of their time away from the nest of ten returning with food or building material, but they are seldom involved in Dominance 
Behaviour, Dominance Display or Egg Laying. Notice however, that they show a very high frequency of subordinate behaviour. These individuals thus constitute the principal worker force on the nest and are unlikely to be involved in reproductive competition with their nest mates.

We have recently completed a very similar study with a related species of social wasp, R. marginata (GADAGKAR and JosHI 1983) and it is of obvious interest to compare the results of the present study with those of $R$. marginata. Using multivariate analysis of time-activity budget data, individuals of $R$. marginata were also classified into three behavioural clusters: Sitters, Fighters and Foragers. However, there was one important difference. The queens of $R$. marginata were amongst the Sitters while the principical egg layers of $R$. cyathiformis are the Fighters except when they had no one to compete with (animals 26 and 27). The nests of $R$. marginata studied were monogynous, the queens did little other than Sit and Groom and Lay Eggs. Although they appeared to be at the top of the dominance hierarchy, they seldom engaged in actual physical interaction with their nest mates. On the other hand at least one of the nests of $R$. cyatbiformis (nest 1 , the nest from which most of the animals in this study are derived) was polygynous; the principal egg layers (which we interpret as corresponding to the queens of $R$. marginata) showed the highest frequency of Dominance Behaviour and Display. For these and similar reasons, we have recently argued that $R$. cyathiformis is at a somewhat more primitive level of social organization than $R$. marginata (GADAGKAR and JosH $1982 \mathrm{~b}$ ). The fact that the queens of $R$. marginata are Sitters and the principal egg layers of $R$. cyathiformis are Fighters suggests a much greater degree of reproductive competition by overt dominance behaviour in $R$. cyathiformis than in $R$. marginata, at least in so far as the nests we have studied are concerned. Furthermore, the two queens of $R$. cyathiformis, 26 and 27, on single foundress nests who did not have any other wasps to compete with were Sitters.

One other difference between the two species that needs to be mentioned is the fact that in $R$. marginata, males are produced only very late in the colony cycle and disappear from the nest within two or three days after emergence (GADAGKAR and JosHI 1983). On the contrary in R. cyathiformis males are sometimes produced relatively early in the colony cycle (GADAGKAR unpubl. obs.) and stay on at the nest for long periods of time (Fig. 6). This is perhaps further evidence of the primitiveness of the $R$. cyatbiformis social system. Recall that some of the Sitters and even some of the Foragers in $R$. cyathiformis laid some eggs. In a situation such as this it is possible that some unmated females lay a few haploid male-producing eggs. Queen-worker conflict and the success of workers in sneaking in a few of their own male eggs or replacing the queen's male eggs with their own are all well known in Hymenoptera (WILson 1971).

Apart from $R$. marginata and $R$. cyathiformis there is another instance of a similar study in social insects. This is the study of BRoTHERS and MicHENER (1974) who subjected rather similar data on the primitively eusocial bee 
Lasioglossum zephyrum to principal components analysis. Their bees also clustered into three groups which they call Queens, Guards and Workers.

We have speculated before (GADAGKAR and JosHI 1983) that the Queens, Guards and Workers of L. zephyrum correspond to the Sitters, Fighters and Foragers of $R$. marginata. It is possible that such a behavioural caste differentiation into three groups with Sitting, Fighting and Foraging as their main attributes is a common feature of primitively eusocial insects. Our analysis of time-activity budgets of another primitively eusocial wasp, Polistes versicolor, also shows the presence of behavioural caste differentiation into Sitters, Fighters and Foragers (GADAGKar and Joshi in prep.). LrTTE (1981) who studied another primitively eusocial wasp Mischocyttarus labiatus in Colombia showed that the colonies are composed of three kinds of females: egg-layers; nonforaging, aggressive females; and non-aggressive foragers.

\section{Zusammenfassung}

Imagines der primitiv eusozialen indischen Wespe Ropalidia cyatbiformis wurden iridividuell markiert. Ihre Zeit- und Aktivitätsaufteilung belegt die Existenz dreier Ethotypen (oder Kasten), die nach ihrem typischen Verhalten als Kämpfer, Sitzer und Futtersucher bezeichnet werden. Eierleger und zugleich die dominantesten Tiere sind hauptsächlich die Kämpfer. Die Sitzer sind "Faulenzer", vermutlich künftige Königinnen. Die Futtersucher sind die hauptsächlichen Arbeitskräfte. Diese Verhaltensdifferenzierung scheint sich normalerweise nicht mit dem Alter der Tiere zu ändern. Das Verhalten ändert sich auch nicht, wenn das Individuum sein Nest verläßt und ein anderes gründet oder sich einem anderen anschließt. Es ist jedoch möglich, daß es sich als Reaktion auf einschneidende Zwischenfälle, wie z. B. Tod der Königin, ändert. Männliche Wespen bilden keine von den Weibchen unterschiedene Gruppe, sondern sind entweder Sitzer oder Futtersucher. Ein Vergleich dieser Ergebnisse mit denen bei $R$. marginata, einer verwandten sozialen Wespe, deren Königinnen Sitzer sind, weist darauf hin, daß bei $R$. cyatbiformis ein stärkerer Fortpflanzungswettbewerb besteht.

\section{Acknowledgements}

We thank Madhav Gadgil, C. D. Mrchener, Mary Jane West-Eberhard, R. W. Mathews, H. Sharat Chandra and E. G. Leigh Jr. for critically reviewing an earlier draft of this manuscript and R. LAKSHMinarayanan for the German translation of the summary.

\section{Literature Cited}

Altmann, J. (1974): Observational study of behaviour: Sampling methods. Behaviour 49, 227-265 - Anderberg, J. (1973): Cluster analysis for Applications. Acad. Press, New York.

Breed, M. D., C. D. Mrchener and H. E. Evans, eds. (1982): The Biology of Social Insects. Proc. IXth Congr. Int. Union for the Study of Social Insects, Boulder, Westview 
Press, Colorado - Brothers, D. J., and C. D. Michener (1974): Interaction in colonies of primitively social bees. III. Ethometry of division of labor in Lasioglossum zephyrum (Hymenoptera: Halictidae). J. Comp. Physiol. 90, 129-168.

De Ghetr, V. J. (1978): Hierarchical cluster analysis. In: Quantitative Ethology. (CoLGaN, P. W., ed.), John Wiley and Sons, New York, pp. 115-144.

Frey, D. F., and R. A. Pimentel (1978): Principal component analysis and factor analysis. In: Quantitative Ethology. (Colgan, P. W., ed.), John Wiley and Sons, New York, pp. 219-245.

Gadagkar, R. (1980): Dominance hierarchy and division of labor in the social wasp, Ropalidia marginata (Lep.) (Hymenoptera: Vespidae). Curr. Sci. 49, 772-775 • GAdagkar, R., and N. V. Joshi (1982a): A comparative study of social structure in colonies of Ropalidia. In: The Biology of Social Insects. Proc. IXth Congr. Int. Union for the Study of Social Insects, Boulder (Breed, M. D., C. D. Michener and H. E. Evans, eds.) Westview Press, Boulder, Colorado, pp. 187-191 - Gadagkar, R., and N. V. Joshi (1982b): Behaviour of the Indian Social Wasp Ropalidia cyathiformis (Fab.) on a nest of separate combs (Hymenoptera: Vespidae). J. Zool. Lond. 198, 27-37 - GadAGKAR, R., and N. V. JoshI (1983): Quantitative ethology of social wasps: Time-activity budgets and caste differentiation in Ropalidia marginata (Lep.) (Hymenoptera: Vespidae). Anim. Behav. 31, 26-31 - GAdagKar, R., M. GADGIL and A. S. MaHabal (1978): Observations on population ecology and sociobiology of the paper wasp Ropalidia marginata (Lep.) (Hymenoptera: Vespidae). Proc. Symp. Ecol. Anim. Pop. Zool. Surv. India, Calcutta - Gadagkar, R., M. Gadgil, N. V. Joshi and A. S. Mahabal, (1982): Observations on the natural history and population ecology of the wasp Ropalidia marginata (Lep.) from Peninsular India (Hymenoptera: Vespidae). Proc. Ind. Acad. Sci. (Animal Sciences) 91, 539-552 - GadGIL, M., and A. S. Mahabal (1974): Caste differentiation in the paper wasp Ropalidia marginata (Lep.). Curr. Sci, 43, 482 - GamBOA, G. J., and H. E. DEW (1981): Intracolonial communication by body oscillations in the paper wasp, Polistes metricus. Insectes Sociaux 28, 13-26 - GREENBERG, L. (1979): Genetic component of bee odor in kin recognition. Science 206, 1095-1097 - GuPTA, V. K., and B. P. DAs (1977): Distributional patterns of Indian Vespidae (Hymenoptera) with reference to altitude. Entomon 2, 209-213.

Hunt, J. M., and K. C. Noonan (1979): Larval feeding by male Polistes fuscatus and Polistes metricus (Hymenoptera: Vespidae). Insectes Sociaux 26, 247-251.

JEANNE, R. L. (1972): Social biology of the neotropical wasp Mischocyttarus drewseni. Bull. Mus. Comp. Zool. Harv. Univ. 144, 63-150 - JEAnNE, R. L. (1980): Evolution of social behaviour in the Vespidae. Ann. Rev. Entomol. 25, 371-396.

LiTre, M. (1977): Behavioural ecology of the social wasp Mischocyttarus mexicanus. Behav. Ecol. Sociobiol. 2, 229-246 - LrTte, M. (1979): Mischocyttarus flavitarsis in Arizona: social and nesting biology of a polistine wasp. Z. Tierpsychol. 50, 282-312 - LITTE, M. (1981): Social biology of the polistine wasp Mischocyttarus labiatus: survival in a Colombian rain forest. Smithson. Contr. Zool. No. 327.

Marino Piccioli, M. T., and L. Pardi (1970): Studi sulla biologia di Belonogaster (Hymenoptera, Vespidae) 1. Sull. etogramma di Belonogaster griseus (Fab.). Monitore Zool. ital. Suppl. 3, 197-255 - Marino Picciolr, M., and L. PArdi (1978): Studies on the biology of Belonogaster (Hymenoptera, Vespidiae) 3. The nest of Belonogaster griseus (Fab.). Monitore Zool. ital. Suppl. 10, 179-228 - Michener, C. D. (1974): The Social Behaviour of the Bees. Harvard Univ. Press, Cambridge, Mass.

Pard, L. (1948): Dominance order in Polistes wasps. Physiol. Zool. 21, 1-13 - Pard, L., and M. T. Marino Prccioli (1970): Studi sulla biologia di Belonogaster (Hymenoptera, Vespidae) 2. Differenziamento castale incipiente in B. griesus (Fab.). Monitore Zool. ital. Suppl. 3, 235-265 - Pardi, L., and M. T. Marino Piccioli (1981): Studies on the biology of Belonogaster (Hymenoptera: Vespidae) 4. On caste differences in Belonogaster griseus (Fab.) and the position of this genus among social wasps. Monitore Zool. ital. Suppl. 14, 131-146 Pickering, J. (1980): Sex Ratio, social behaviour and ecology in Polistes (Hymenoptera, Vespidae), Pachysomoides (Hymenoptera, Ichneumonidae) and Plasmodium (Protozoa, Haemosporidia) Ph. D. Thesis, Havard Univ. Press, Cambridge, Mass.

Richards, O. W. (1978): The Australian social wasps (Hymenoptera: Vespidae), Aust. J. Zool. Suppl. Ser. No. 61, 1-132. 
Soxal, R. R., and F. J. RohlF (1969): Biometry. W. H. Freeman and Co., San Francisco - Strassmann, J. E. (1981a): Evolutionary implications of early male and satellite nest production in Polistes exclamans colony cycles. Behav. Ecol. Sociobiol. 8, 55-64 - StrassmanN, J. E. (1981b): Parasitoids, predators, and group size in the paper wasp, Polistes exclamans. Ecology 62, 1225-1233.

VECHT, J. VAN DER (1962): The Indo-Australian species of the genus Ropalidia (Icaria) (2nd part). Zool. Verhand. Leiden 57, 1-72.

WEST, M. J. (1967): Foundress associations in polistine wasps: Dominance hierarchies and the evolution of social behaviour. Science 157, 1584-1585 - WEST-EBERHARD, M. J. (1969): Social biology of polistine wasps. Misc. Publ. Mus. Zool. Univ. Mich. 140, 1-101 • WEST-EBerhard, M. J. (1978): Temporary queens in Metapolybia wasps: non-reproductive helpers without altruism? Science 200, 441-443 - WILsON, E. O. (1971): The Insect Societies. Harvard Univ. Press, Cambridge, Mass. • Wilson, E. O. (1975): Sociobiology. Harvard Univ. Press, Cambridge, Mass.

Authors' address: Raghavendra GADAGKar and N. V. Joshi, Center for Theoretical Studies, Indian Institute of Science, Bangalore-560 012, India. 